Gut, 1960, 1, 217.

\title{
AN ASSESSMENT OF PREDNISONE, SALAZOPYRIN, AND TOPICAL HYDROCORTISONE HEMISUCCINATE USED AS OUT-PATIENT TREATMENT FOR ULCERATIVE COLITIS
}

\author{
BY \\ J. E. LENNARD-JONES,* A. J. LONGMORE, A. C. NEWELL, C. W. E. WILSON, \\ and F. AVERY JONES
}

From St. Mark's Hospital, London

Two consecutive trials of out-patient treatment for mild cases of active ulcerative colitis are described. In the first trial oral prednisone gave significantly better results than a placebo. In the second trial "salazopyrin" gave final results approaching those of prednisone, although over a longer time and with a higher incidence of unpleasant side-effects, but topical hydrocortisone gave disappointing results, probably because the technique of administration was not suitable for ordinary out-patient use.

Controlled trials have shown that three treatments-oral cortisone (Truelove and Witts, 1955), topical hydrocortisone hemisuccinate sodium (Truelove, 1958b; Watkinson, . 1958), and topical prednisolone 21-phosphate (Matts, 1960)-favourably influence the course of active ulcerative colitis. By comparative trial with cortisone, corticotrophin is also known to be effective (Truelove and Witts, 1959). Much information (Svartz, 1956; Moertel and Bargen, 1959) has now been accumulated indicating that "salazopyrin" $\dagger$ is another effective drug, though a prospective controlled trial is so far lacking.

During the years 1956-59, three remedies-oral prednisone, topical hydrocortisone, and "salazopyrin"-have been assessed in the medical outpatient clinic at St. Mark's Hospital. The investigation was done in two stages, each a separate trial, and preliminary results of both have been reported (Newell and Avery Jones, 1958; LennardJones, Longmore, and Avery Jones, 1960). In the first stage, during 1956 and 1957, the effectiveness of oral prednisone was compared with that of calcium lactate, assuming this to be an inert substance. This trial established prednisone as an effective treatment. In the second stage, during 1958 and 1959, prednisone was used as a standard

* Member Medical Research Council Department of Clinical Research, University College Hospital Medical School.

† Salicylazosulphapyridine. with which "salazopyrin" and hydrocortisone hemisuccinate retention enemata therapy could be compared.

\section{Method of Study}

Selection of Patients and Allocation of TreatMENTS.-The patients selected for these trials were suffering from active ulcerative colitis involving part or all of the colon distal to the splenic flexure. All were treated as out-patients, all suffered little or no systemic upset from their disease, and all were eligible for any of the treatments under trial. In the first stage of the trial 19 patients whose hospital number was even were given prednisone and 18 patients with an odd number were given calcium lactate. The second stage of the trial included 60 patients, 20 treated with each of three remedies. After patients had been included in this stage, treatment was allocated by blindly drawing a slip from a box containing 60 slips, 20 marked with each treatment. The 97 trials of treatment in the two stages involved 92 different patients. No patient was included twice in either stage of the trial but five patients were included in both the first and second stages.

Comparabitity of the Treatment Groups.-By the criteria for selection of patients the severity of the disease should be comparable in the different treatment groups. The data on patients' symptoms shown in Table I suggest that this is so. Fewer first attacks of disease were treated in the calcium lactate and topical hydrocortisone groups. It is doubtful if this affects the final results as none of the patients treated during a first attack were benefited by calcium lactate and only one by topical hydrocortisone. 
TABLE I

COMPARABILITY OF THE TREATMENT GROUPS

\begin{tabular}{|c|c|c|c|c|c|c|c|c|}
\hline & \multirow[b]{2}{*}{$\begin{array}{l}\text { No. of } \\
\text { Patients }\end{array}$} & \multirow[b]{2}{*}{ Mean Age } & \multirow[b]{2}{*}{ Males } & \multirow{2}{*}{$\begin{array}{c}\text { Treated } \\
\text { for First } \\
\text { Attack }\end{array}$} & \multirow{2}{*}{$\begin{array}{c}\text { Treated } \\
\text { for } \\
\text { Relapse }\end{array}$} & \multicolumn{3}{|c|}{ Symptoms } \\
\hline & & & & & & $\begin{array}{l}\text { Diarrhoea } \\
\text { and } \\
\text { Bleeding }\end{array}$ & $\begin{array}{l}\text { Bleeding } \\
\text { Only }\end{array}$ & $\begin{array}{c}\text { Diarrhoea } \\
\text { Only }\end{array}$ \\
\hline Prednisone (1) & 19 & 38 & 8 & 7 & 12 & 11 & 8 & 0 \\
\hline Calcium lactate & 18 & 41 & 7 & 3 & 15 & 8 & 10 & $\mathbf{0}$ \\
\hline Prednisone $†$ (2) & 12 & 40 & 4 & 3 & 9 & 4 & 8 & 0 \\
\hline Salazopyrin & 20 & $\left(3 . \mathbf{3}^{8}\right)$ & 7 & 10 & 10 & 11 & 8 & 1 \\
\hline Prednisone (3) & 20 & 44 & 8 & 8 & 12 & 13 & 7 & 0 \\
\hline Topical hydrocortisone & 20 & $\begin{array}{l}\text { (S.D. } \\
\text { (S.D) } \\
\text { (S.D. 17) }\end{array}$ & 12 & 5 & 15 & 13 & 7 & 0 \\
\hline
\end{tabular}

† After failure of calcium lactate.

Assessment of Results.-Patients' symptoms were recorded at each visit and subsequently classified as:-

"No change or (Compared with the symptoms beworse" $\quad$ fore treatment and judged from the patient's statements about frequency of bowel action and bleeding. (A general sense of well-being alone was not accepted as indicating improve(ment.)

"No symptoms" Normal bowel actions without bleeding or discharge. (An occasional streak of blood on a normal stool was accepted as freedom from symptoms.)

Sigmoidoscopy was performed at each visit and the appearances were classified as:-
"Active" =oedematous, friable mucosa, no granularity

"Moderately active" = moist granular, friable mucosa

"Inactive" =dry, granular, not friable mucosa

"Normal" =vascular pattern visible throughout

Improvement or deterioration was recognized if the appearance on one visit was in a different category from that on another.

"Remission" of the disease is defined as freedom from symptoms combined with the finding of an inactive or, rarely, normal mucosa on sigmoidoscopy. Freedom from symptoms with an active mucosa or vice versa did not constitute "remission". "Improvement" on overall assessment usually indicated improvement in both symptoms and sigmoidoscopic appearance.

TABLE II

DURATION OF TREATMENT AND TOTAL DOSE OF DRUG UNTIL REMISSION OR UNTIL END OF TREATMENT Stage 1:

\begin{tabular}{|c|c|c|c|c|c|c|c|c|c|}
\hline & \multicolumn{3}{|c|}{ Prednisone } & \multicolumn{3}{|c|}{ Calcium Lactate } & \multicolumn{3}{|c|}{$\begin{array}{l}\text { Prednisone after Failure of } \\
\text { Calcium Lactate }\end{array}$} \\
\hline & Remission & Improved & No Benefit & Remission & Improved & No Benefit & Remission & Improved & No Benefit \\
\hline $\begin{array}{l}\text { Number of patients } \\
\text { Weeks of treatment } \\
\text { (mean and range) } \\
\text { Total dose (g.) } \\
\text { (mean and range) }\end{array}$ & $\begin{array}{c}13 \\
3 \cdot 5 \\
(1-10) \\
1 \cdot 0 \\
(0 \cdot 4-2 \cdot 4)\end{array}$ & $\begin{array}{c}4 \\
11 \cdot 3 \\
(6-20) \\
2 \cdot 2 \\
(1 \cdot 5-3 \cdot 4)\end{array}$ & $\begin{array}{c}2 \\
4 \\
(3-5) \\
1 \cdot 4 \\
(1 \cdot 3-1 \cdot 4)\end{array}$ & $\begin{array}{c}3 \\
8 \\
(4-14) \\
-\end{array}$ & $\begin{array}{c}3 \\
10 \\
(3-20) \\
=\end{array}$ & $\begin{array}{c}12 \\
4 \cdot 4 \\
(1-15) \\
= \\
-\end{array}$ & $\begin{array}{c}9 \\
5 \cdot 7 \\
(1-12) \\
1 \cdot 3 \\
(0 \cdot 4-2 \cdot 2)\end{array}$ & $\begin{array}{l}- \\
z\end{array}$ & $\begin{array}{c}3 \\
8 \cdot 7 \\
(8-9) \\
2 \cdot 0 \\
(1 \cdot 5-2 \cdot 6)\end{array}$ \\
\hline
\end{tabular}

Stage 2:

\begin{tabular}{|c|c|c|c|c|c|c|c|c|c|}
\hline & \multicolumn{3}{|c|}{ Salazopyrin } & \multicolumn{3}{|c|}{ Prednisone } & \multicolumn{3}{|c|}{ Topical Hydrocortisone } \\
\hline & Remission & Improved & No Benefit & Remission & Improved & No Benefit & Remission & Improved & No Benefit \\
\hline $\begin{array}{l}\text { Number of patients } \\
\text { Weeks of treatment } \\
\text { (mean and range) } \\
\text { Total dose (g.) } \\
\text { (mean and range) }\end{array}$ & $\begin{array}{c}8 \\
8 \cdot 5 \\
(2-16) \\
154 \\
(20-308)\end{array}$ & $\begin{array}{c}5 \\
24 \\
(3-52) \\
310 \\
(54-532)\end{array}$ & $\begin{array}{c}7 \\
7 \\
(0-21) \\
104 \\
(0-354)\end{array}$ & $\begin{array}{c}11 \\
3.9 \\
(3-8) \\
1 \cdot 1 \\
(0.9-1 \cdot 9)\end{array}$ & $\begin{array}{c}5 \\
9 \cdot 8 \\
(3-19) \\
1 \cdot 8 \\
(0 \cdot 9-3 \cdot 1)\end{array}$ & $\begin{array}{c}4 \\
5 \cdot 5 \\
(5-6) \\
1 \cdot 3 \\
(1 \cdot 2-1 \cdot 6)\end{array}$ & $\begin{array}{c}3 \\
3 \cdot 7 \\
(3-5) \\
2 \cdot 6 \\
(2 \cdot 1-3 \cdot 5)\end{array}$ & $\begin{array}{c}5 \\
11 \cdot 4 \\
(3-21) \\
5 \cdot 5 \\
(2 \cdot 1-8 \cdot 7)\end{array}$ & $\begin{array}{c}12 \\
3 \\
(0-8) \\
2 \cdot 2 \\
(0-5 \cdot 6)\end{array}$ \\
\hline
\end{tabular}

The mean time between the start of treatment and remission of the disease was significantly $(P=<0.02, t=2.79, n=17)$ longer with "salazopyrin" ( 8.5 weeks) than with prednisone (3.9 weeks). The first assessment was made at three or four weeks; nine out of 11 remissions during prednisone treatment occurred by this time, compared with two out of eight remissions during "salazopyrin" therapy. 


\section{RESULTS}

Stage 1: Comparison between Prednisone and CALCIUM LACTATE.-In this trial the treatment determined by the patient's hospital number was given for three to four weeks; both doctor and patient knew which treatment was given. If at the end of this time there was no improvement after treatment with calcium lactate, prednisone was substituted; calcium lactate was not substituted if prednisone failed. In one case treatment with calcium lactate was stopped and prednisone substituted after one week and in another case after two weeks, because of worsening of the illness. If a patient's condition improved, treatment was continued until full remission was achieved, or until the maximum benefit had apparently resulted, when it was withdrawn. Prednisone was given in a dose of 40 to $60 \mathrm{mg}$. daily for the first week and then the dose was slowly reduced; calcium lactate was given in a dose of $1.3 \mathrm{~g}$. daily.

The overall results of treatment are shown in Fig. 1. Of the 19 patients treated initially with prednisone, remission was achieved in 13 , nine of them being in remission within three weeks of starting treatment. In the corresponding group given calcium lactate remission was achieved in three out of 18 patients. Only two out of 19 patients received no benefit from prednisone whereas 12 out of 18 patients received no benefit from calcium lactate. These 12 patients in whom calcium lactate had failed were given prednisone and remission occurred in nine of them. Although numbers are small, remission perhaps occurred earlier among those treated with prednisone than among those treated with calcium lactate (Table II). The difference between the number of remissions which occurred with prednisone and with calcium lactate given as first treatments is such as would have occurred by chance less than once in 100 times.

Stage 2: Comparison between Salazopyrin, HYDROCORTISONE RETENTION ENEMATA, AND PrRDNISONE.-Preliminary results of this trial with the technique and doses used have already been reported (Lennard-Jones et al., 1960). Briefly, after a patient had been included in the trial, one of the three treatments was allocated by random selection. Again, both doctor and patient knew which treatment was given. Patients were usually seen after treatment for three weeks. If there was no improvement by this time the treatment was considered a failure and the trial ended. If there was definite or possible improvement the treatment was continued in reduced dosage until remission or apparent maximum benefit was achieved, and it was then slowly withdrawn. For the first three weeks, "salazopyrin" was given in a total dose of $4 \mathrm{~g}$. daily; hydrocortisone (as hemisuccinate sodium), $100 \mathrm{mg}$. freshly dissolved in $150 \mathrm{ml}$. of normal saline as a retention enema nightly, using the modified blood transfusion set described by Truelove (1958a); and prednisone in a total dose of $60 \mathrm{mg}$. daily for the first week, $45 \mathrm{mg}$. daily for the second week, and $30 \mathrm{mg}$. daily for the third week.

After the first three weeks the greatest number of patients was free of symptoms after prednisone, the fewest after hydrocortisone retention enemata; "salazopyrin" gave intermediate results. The final assessment of the three treatments is shown in Fig. 2. Of the 20 patients treated with each remedy, remission occurred in 11 patients given prednisone (seven of them within three weeks of starting treatment), eight given "salazopyrin", and three treated with hydrocortisone retention enemata. Remission was achieved significantly $(P=<0.02)$ sooner with prednisone than with "salazopyrin" (Table II). The difference between the number of remissions which occurred during treatment with prednisone and with topical hydrocortisone is such as would have occurred by chance less than once in $\mathbf{5 0}$ times. The number of remissions which occurred during treatment with "salazopyrin" is not significantly different from the number which occurred during calcium lactate, topical hydrocortisone, or prednisone therapy.

Side-EFfects From Treatment.-Of the 51 patients treated with prednisone during the two stages of the trial, 17 complained of side-effects, two of whom found it necessary to reduce the dose during the first three weeks. None of the side-effects were serious and all disappeared when the dose was reduced; we are not aware of any long-term harm from steroid treatment among these patients, all but two of whom have been followed for more than six months after ending treatment. The symptoms complained of were mooning of the face (7), dyspepsia (5), acne (4), gain in weight (2), palpitations (2), flushes (1), and syncopal attacks (1).

Two patients treated with calcium lactate developed side-effects, heartburn (1) and "pimples" (1).

Twelve patients out of the 20 treated with "salazopyrin" complained of unpleasant side-effects, namely, nausea (4), anorexia (3), vomiting (2), malaise (2), diarrhoea (1), and skin rash (1). Three patients (accounting for three out of five failures of the treatment) could not take the drug even in small doses, five others could only take a reduced dose (Fig. 2). We have not observed any haematological complications.

One patient complained of colic after the retention enemata. 


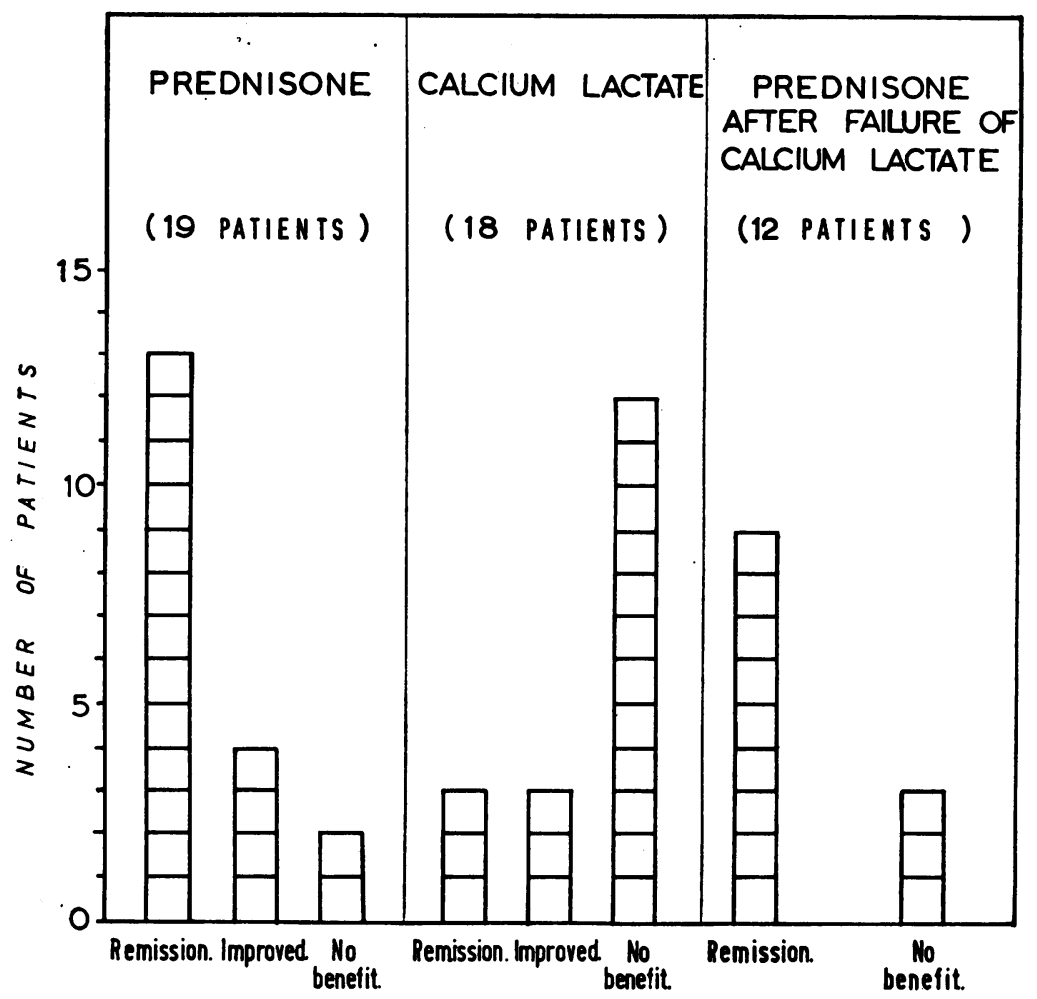

Fig. 1.-The results of treatment with prednisone and calcium lactate. The number of patients in whom remission of the disease occurred was significantly greater during initial treatment with prednisone than during treatment with calcium lactate $\left(\left(\chi_{\mathrm{c}}^{2}=10 \cdot 1\right.\right.$, $n=1, P=<0.01)$.

FIG. 2.-The results of treatment with "salazopyrin", prednisone, and topical hydrocortisone. The number of patients in whom remission of the disease occurred was significantly greater during treatment with prednisone than during treatment with topical hydrocortisone $\left(\chi^{2} \mathrm{c}\right.$ $=6.6, n=1, P=<0.02)$.

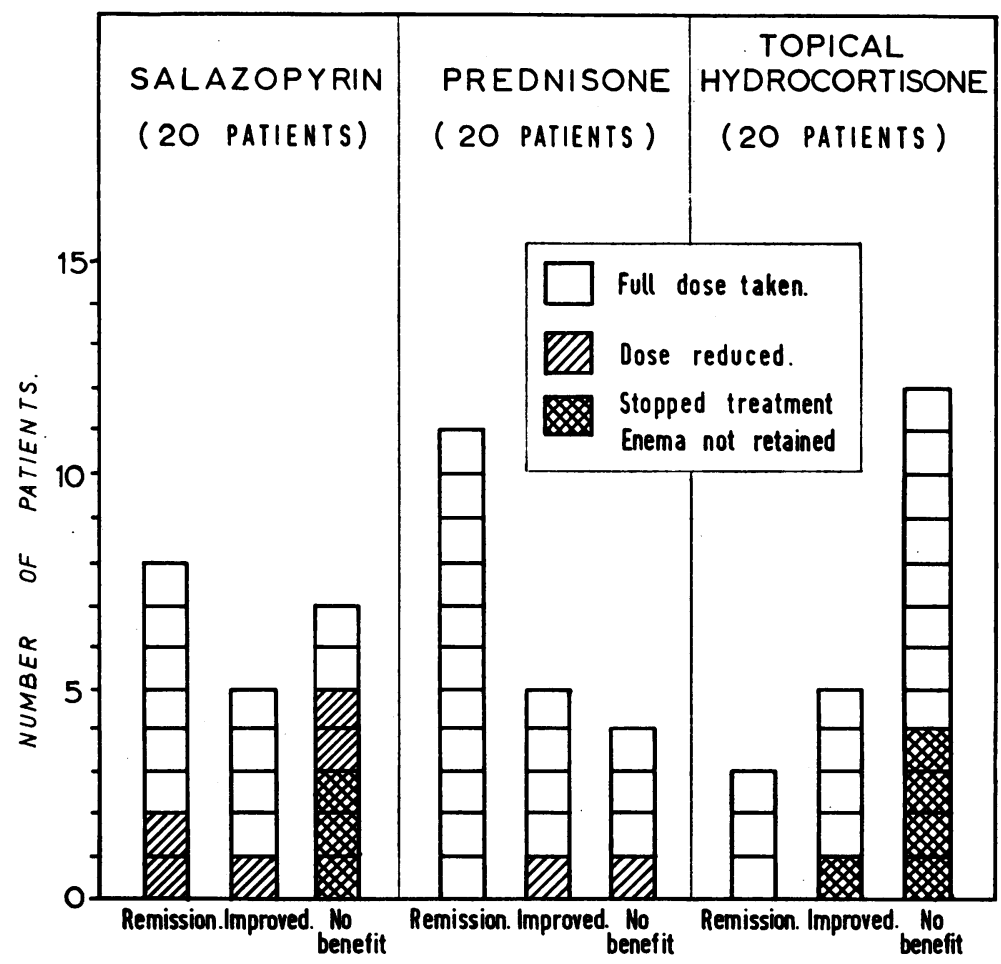


Relapse Rate after Remission Achieved.Nineteen of the 33 patients in remission after treatment with prednisone relapsed during the next six months (follow-up incomplete in two patients). The illness in four became active again as treatment was withdrawn at daily doses of $15,10,5$, and $5 \mathrm{mg}$. respectively. Of the 12 patients in remission at six months, four patients relapsed during the next six months and four more between one and two years; only three patients have remained in remission for more than two years (one patient has remained in remission for 21 months; follow-up for two years is incomplete). The numbers in remission after the other treatments are too small to draw valid conclusions about the rate of relapse.

\section{Discussion}

The usefulness of cortisone in ulcerative colitis has been firmly established by the Medical Research Council trial (Truelove and Witts, 1955). We know of no other controlled trials of oral corticosteroid therapy in this disease. The present trial differs from the M.R.C. trial in several ways. First, all the patients suffered from mild, though active, disease and were treated as out-patients. Second, a different drug, prednisone, was used, specially selected for its anti-inflammatory effect. Third, patients were treated with initial high doses followed by a rapid reduction. Even though a double-blind trial was not performed, the results appear to establish the usefulness of prednisone as out-patient treatment; no lasting harmful effects of treatment occurred with the régime described. The remission rate in the M.R.C. trial among mild cases was $75 \%$ and among cases of moderate severity $31 \%$ at the end of six weeks. Our cases would fall into these two categories and the remission rate of $65 \%$ in this series appears comparable.

The effectiveness of "salazopyrin" as treatment for ulcerative colitis has been described by many authors (Svartz, 1956; Moertel and Bargen, 1959), but there has been a notable dearth of contemporary controlled observations. The present investigation suggests that "salazopyrin" is a useful drug. Its main advantage is that it does not cause adrenal suppression or other potential hazards of corticosteroid therapy. It suffers the disadvantages of relatively slow action compared with prednisone and of frequently causing unpleasant side-effects, perhaps especially noticeable by out-patients who feel otherwise well.

The results of hydrocortisone retention enema therapy in this series were disappointing. The technique used was cumbersome and complicated, suitable more for hospital than out-patient use. No attempt was made to select patients for this treatment who were adaptable, intelligent, and without aversion to the idea of self-administration of enemata. Five out of 20 patients failed to retain the enemata (one because of diarrhoea and three because of inability to carry out the treatment unaided), but even among the remainder results were unsatisfactory. We believe that topical corticosteroid treatment can be very effective as Truelove (1958b) and Watkinson (1958) have shown. Techniques such as the disposable enema bags described by Flavell Matts (1960) should make this type of therapy more convenient for out-patient use. Hydrocortisone given rectally is absorbed to some extent (Nabarro, Moxham, Walker, and Slater, 1957) and it seems worth pointing out that large total doses of hydrocortisone may be given during maintenance treatment with retention enemata; one of our patients received $8.7 \mathrm{~g}$. over 21 weeks.

From this trial we conclude that oral prednisone brings about rapid remission of the disease in a high proportion of cases and that "salazopyrin" probably brings about remission almost as frequently, though more slowly. Since systemic corticosteroid treatment is potentially dangerous we suggest that it is best in most cases to start treatment with "salazopyrin" or topical corticosteroid treatment, using one of the newer techniques. The high relapse rate after successful treatment with prednisone shows that the greatest need at present is for a drug which will prevent relapse once remission is achieved.

\section{SUMMARY}

(1) A controlled trial against a placebo demonstrated the effectiveness of oral prednisone as an out-patient treatment for active left-sided ulcerative colitis.

(2) In a comparative trial, performed consecutively, prednisone gave the best results; "salazopyrin" gave final results approaching those of prednisone, but more slowly and with a higher incidence of side-effects; topical hydrocortisone gave disappointing results, probably largely due to the technique of administration used. Statistical evidence for the effectiveness of "salazopyrin" was not obtained. The results from prednisone were significantly better than those from topical hydrocortisone.

(3) Remission occurred in 33 out of 51 patients treated with prednisone during the two stages of the trial, often within three weeks of starting treatment. Relapse of the illness occurred among more than half of these patients during the next six months. 
No dangerous side-effects resulted from the treatment.

We thank the consultant staff of the hospital for referring patients included in this study, members of the Records and Research Departments for their help, and Glaxo Laboratories for the hydrocortisone hemisuccinate sodium used in the trial. Expenses of the study were met from a research grant by the Board of Governors of the Hammersmith and St. Mark's group of hospitals.

\section{REFERENCES}

Lennard-Jones, J. E., Longmore, A. J., and Jones, F. Avery (1960). Proc, roy. Soc. Med. In course of publication.

Matts, S. G. Flavell (1960). Lancet, 1, 517.

Moertel, C. G., and Bargen, J. A. (1959). Ann. intern. Med., 51, 879. Nabarro, J. D. N., Moxham, Audrey, Walker, G., and Slater, J. D. H. (1957). Brit. med. J. 2, 272

Newell, A. C., and Jones, F. Avery (1958). Proc. roy. Soc. Med., 51,431 .

Svartz, (1956), Gastroenterologia (Basel), 86, 683.

Truelove, S. C. (1958a). Proc. roy. Soc. Med., 51, 429.

(1958b). Brit. med. J., 2, 1072.

, and Witts, L. J. (1955). Ibid., 2, 1041.

Watkinson, G. (1958). Ibid., 2, 1077. 